\title{
An Engaging CS1 Curriculum Using BRIDGES
}

\author{
Matthew Mcquaigue, Allie Beckman, \\ David Burlinson Luke Sloop, Alec Goncharow, \\ Erik Saule, Kalpathi Subramanian \\ \{mmcquaig,abeckma2,dburlins,lsloop4\}@uncc.edu \\ \{agoncha1,krs,esaule\}@uncc.edu \\ The University of N. Carolina
}

\begin{abstract}
Early programming courses such as CS1 are an important time to capture the interest of students while imparting critical technical knowledge. Yet many CS1 courses are being taught using toy assignments and activities that tend to make students uninterested or doubt the usefulness of the content. In this poster, we demonstrate an enriching experience for students by coupling interesting datasets with visual representations and interactive applications, without having to change the content of that course. Our approach utilizes extensions to BRIDGES, an API in use for sophomore level CS courses for the past 5 years. BRIDGES provides easy access to external datasets and helps build interactive applications. The assignments we present are all scaffolded in a way that can be directly integrated into most early programming courses to make routine topics compelling and exciting.
\end{abstract}

\section{KEYWORDS}

real-world datasets, games, engagement

ACM Reference Format:

Matthew Mcquaigue, Allie Beckman,, David Burlinson Luke Sloop, Alec Goncharow, Erik Saule, Kalpathi Subramanian, and Jamie Payton. 2020. An Engaging CS1 Curriculum Using BRIDGES. In The 51st ACM Technical Symposium on Computer Science Education (SIGCSE '20), March 11-14, 2020, Portland, OR, USA. ACM, New York, NY, USA, 1 page. https://doi.org/10. $1145 / 3328778.3372609$

\section{PROBLEM}

Enrollments in computing majors have grown significantly in recent years, however, high attrition rates remain a significant issue. A key factor influencing student motivation is their engagement with learning materials. Traditional approaches in early CS courses have been to teach basic programming constructs (loops, conditionals, objects) using toy datasets and command line input. More engaging and modern approaches generally involve socially or culturally relevant data, simple graphical libraries, and gamification of the material. All these features are prioritized in our work.

\section{METHODS}

BRIDGES[1] is a toolkit that we have developed and has been in use for the past 5 years, for improving retention of sophomore

Permission to make digital or hard copies of part or all of this work for personal or classroom use is granted without fee provided that copies are not made or distributed for profit or commercial advantage and that copies bear this notice and the full citation on the first page. Copyrights for third-party components of this work must be honored

For all other uses, contact the owner/author(s).

SIGCSE '20, March 11-14, 2020, Portland, OR, USA

(c) 2020 Copyright held by the owner/author(s).

ACM ISBN 978-1-4503-6793-6/20/03.

https://doi.org/10.1145/3328778.3372609

\author{
Jamie Payton \\ payton@temple.edu \\ Temple University
}

Table 1: CS1 Assignments Using BRIDGES

\begin{tabular}{lll}
\hline Assignment & CS1 Concepts & Engagement \\
\hline Etch A Smile & 2D Grids,loops & Visualization \\
Bugstomp & 2D addressing, I/O & Interactive Game \\
Tic Tac Toe & Conditionals, 2D array & Interactive Game \\
Song Lyrics & 2D grid processing, & Real Lyrics data, \\
& String parsing, conditionals & visualizations \\
Image Processing & 2D array processing & External Data, \\
& 1D, 2D addressing & Color models \\
& Memory allocation & Manipulating Images \\
Moutain Path & Loops, conditionals & Greedy algorithms, \\
& 2D addressing, File input & Real-world data, \\
& & Visualizations \\
\hline
\end{tabular}

level CS students. The BRIDGES API facilitates highly engaging assignments using real world datasets and visualizations. Most of the effort to date has focused on data structures and algorithms courses, and has impacted nearly 1500 students across multiple institutions. Over the past year, we have added new features to BRIDGES that facilitates its use in early CS courses, such as CS1 and CS2, including a Game API, that makes it possible to implement a variety of $2 \mathrm{D}$ games.

\section{RESULTS}

We have built a number of BRIDGES assignments that are appropriate for CS1 courses. Table 1 illustrates these assignments and the CS1 topics/objectives that are addressed by each assignment. The BRIDGES assignments website[1] illustrates example assignments and visualizations. These assignments were used in a number of sophomore level courses and surveys used to get student feedback. Results of two questions in the survey, "The assignment increased my interest in computing", "The assignment was relevant to my career goals" on the Mountain Path assignment showed positive feedback from students over two semesters.

\section{CONCLUSIONS}

Several of our BRIDGES users are currently testing these assignments in their early CS courses and collecting student feedback. Future work will involve building a full curriculum and performing a formal intervention in a CS1 course.

\section{REFERENCES}

[1] David Burlinson, Mihai Mehedint, Chris Grafer, Kalpathi Subramanian, Jamie Payton, Paula Goolkasian, Michael Youngblood, and Robert Kosara. 2016. BRIDGES: A System to Enable Creation of Engaging Data Structures Assignments with Real-World Data and Visualizations. In Proceedings of ACM SIGCSE 2016. 18-23. 